\title{
El financiamiento un eje crítico en la sostenibilidad de los emprendimientos en el cantón Riobamba
}

Funding is a critical axis in the sustainability of entrepreneurship in the canton of Riobamba

\author{
William Patricio Cevallos Silva. ${ }^{1}$, Víctor Gabriel Avalos Peñafiel. ${ }^{2}$ \& Germán Patricio \\ Torres Guananga. ${ }^{3}$
}

Recibido: 22-01-2021 / Revisado: 27-01-2021 /Aceptado: 22-02-2021/ Publicado: 05-03-2021

\begin{abstract}
:
DOI: https://doi.org/10.33262/concienciadigital.v4i1.2.1598

Introduction, Jean-Baptiste Say argued that every offer generates its own demand, starting from that statement it is essential to undertake, therefore, this research Objective to determine the sources of financing of the undertakings executed in the Riobamba canton, and at the same time establish the variables that impede access to financing and hinder financial sustainability. Methodology, this study was based on a qualitative and quantitative approach, with a deductive process, the scope was descriptive since a reality is detailed, we worked with a population of 74 enterprises of the Riobamba canton, analytical and synthetic methods were combined. Among the results obtained, it is established that in the Riobamba canton $57 \%$ of the ventures are financed with their own funds, and $27 \%$ are financed with bank credit, Result, it has been determined that one of the main variables that prevent access to financing are the interest rates, which depending on the financial institution vary between 5 and $20 \%$ and even exceed this range, Conclusions, it is important to consider is the Pandemic that has directly impacted on the income of entrepreneurs and therefore on Its profits, this situation, interest rates, among others, are critical factors that affect the financial sustainability of the ventures, and could cause bankruptcy or closure, if the government does not implement rescue policies for this sector, such as the establishment of a unique and preferential interest rate for entrepreneurs.
\end{abstract}

\footnotetext{
${ }^{1}$ Escuela Superior Politécnica de Chimborazo, Facultad de Administración de Empresas, Riobamba, Ecuador, patricio.cevallos@espoch.edu.ec, https://orcid.org/0000-0001-5387-5781

${ }^{2}$ Escuela Superior Politécnica de Chimborazo, Facultad de Administración de Empresas, Riobamba, Ecuador, victor.avalos@espoch.edu.ec, https://orcid.org/0000-0001-8278-7991

${ }^{3}$ Escuela Superior Politécnica de Chimborazo, Facultad de Administración de Empresas, Riobamba, Ecuador, german.torres@espoch.edu.ec, https://orcid.org/0000-0002-5139-1836
} 
Key words: Riobamba, entrepreneurship, financing, sustainability, profits.

\section{Resumen}

Introducción, Jean-Baptiste Say sostenía que toda oferta genera su propia demanda, partiendo de ese enunciado es fundamental emprender, por tanto, esta investigación tiene como Objetivo determinar las fuentes de financiamiento de los emprendimientos ejecutados en el cantón Riobamba, y a la vez establecer las variables que impiden el acceso al financiamiento y que dificultan la sostenibilidad financiera. Metodología, este estudio se fundamentó en un enfoque cualitativo y cuantitativo, con un proceso deductivo, el alcance fue descriptivo ya que se detalla una realidad, se trabajó con una población de 74 emprendimientos del cantón Riobamba, se combinaron los métodos analítico y sintético. entre los resultados obtenidos se establece que en el cantón Riobamba el 57\% de los emprendimientos se financian con fondos propios, y un $27 \%$ se financian con Crédito bancario, Resultado, se ha determinado que uno de las principales variables que impiden el acceso al financiamiento son las tasas de interés, que dependiendo de la institución financiera varían entre el 5 y el $20 \%$ e incluso superan este rango, Conclusiones, es importante a considerar es la Pandemia que ha impactado directamente en los ingresos de los emprendedores y por lo tanto en sus utilidades, esta situación, las tasas de interés entre otros son factores críticos que afectan la sostenibilidad financiera de los emprendimientos, y podría ocasionar la quiebra o el cierre de los mismos, si el gobierno no implementa políticas de rescate a este sector, como el establecimiento de una tasa de interés única y preferencial para los emprendedores.

Palabras clave: Riobamba, emprendimiento, financiamiento, sostenibilidad, utilidades.

\section{Introducción:}

Los emprendimientos desempeñan un rol de gran importancia en la economía nacional, debido a su influencia en la generación de empleo y crecimiento económico, pero también se han evidenciado determinadas falencias que que no les han permitido crecer y ser más competitivas en el mercado ecuatoriano.

De acuerdo con (Lasio \& Zambrano, 2016) la forma de financiar los nuevos negocios ha venido evolucionando en la última década impulsada por una serie de cambios, principalmente en la tecnología e innovación social, de igual manera según los autores (Daniels, Herrington, \& Kew, 2016) en la actualidad "hay mayor emprendimiento, más fuentes de financiamiento, y mejores oportunidades para que individuos y comunidades construyan su futuro económico. sin embargo, con las comunicaciones globales móviles se vuelve evidente que la desigualdad y el acceso a recursos varían considerablemente en todo el mundo".

Uno de los principales problemas del emprendimiento en el cantón Riobamba es la poca sostenibilidad de estos, y una de las razones para esto es la poca oportunidad de acceso a 
fuentes de financiamiento externas, pues solo el $27 \%$ de los emprendedores del cantón han logrado obtener un crédito en las entidades financieras, y en estas operaciones financieras se observa que las tasas de interés son sumamente variables y fluctúan desde el $5 \%$ hasta valores superiores al $20 \%$, esta realidad, en las tasas de interés repercute directamente en la sostenibilidad financiera de los emprendimientos, ya que el endeudamiento si se lo toma a una tasa muy alta afecta directamente a su rentabilidad y en lugar de ser una ayuda para el crecimiento y sostenibilidad podría ocasionar la quiebra o el cierre de los mismos.

Otro problema que se presenta actualmente en los emprendimientos del cantón Riobamba, es la disminución en ventas generada por la pandemia, lo que afecta directamente a sus utilidades, es así que el $49 \%$ de los emprendedores de este cantón generaban una utilidad mensual antes de la emergencia sanitaria entre los 10 y 500 dólares, y el segundo grupo según el número de participantes representa el 32\% de los emprendimientos, y su utilidad estaba entre los 500 y 1000 dólares; Este escenario ha ido cambiando y actualmente se ha incrementa al $65 \%$ la cantidad de emprendedores que generan una utilidad entre 10 y 500 dólares, y el segundo grupo que generaba beneficios entre los 500 y 1000 dólares se redujo al 12\%, es decir este segmento es el más afectado, ya que tuvo una migración del $20 \%$ del total hacia el nivel más bajo, por lo expuesto este estudio servirá de base para la toma de decisiones gubernamentales y de los propios emprendedores que deben establezcan acciones remediales y estrategias sostenibles.

Por lo expuesto el objetivo de esta investigación fue determinar las fuentes de financiamiento de los emprendimientos ejecutados en el cantón Riobamba, y a la vez establecer las variables que impiden el acceso al financiamiento, y que dificultan la sostenibilidad financiera de los emprendimientos.

¿Qué es el emprendimiento?

Según (Martins, 2021) el emprendimiento es la acción de crear un negocio o negocios con el objetivo de generar ganancias. Sin embargo, esta definición básica de lo que es el emprendimiento no abarca todas las posibilidades existentes para los emprendedores. la definición más moderna de emprendimiento también incluye el transformar el mundo resolviendo grandes problemas iniciando un cambio social creando o vendiendo un producto innovador, etc.

¿Qué es el financiamiento?

Según (Raffino, 2000) el financiamiento o financiación es el proceso de viabilizar y mantener en marcha un proyecto negocio o emprendimiento específico mediante la asignación de recursos capitales (dinero o crédito) para él mismo. Dicho más fácilmente financiar es asignar recursos capitales a una iniciativa determinada. 
el financiamiento es un elemento clave en el éxito de cualquier proyecto o empresa, ya que involucra a los recursos que se necesitarán para ponerlo en marcha. todo proyecto requiere, de una u otra manera, de cierto margen de financiación.

Según (Torre, Fresno, \& Centero, 2015) las decisiones de financiación configuran la estructura de capital y deben ir dirigidas a obtener los recursos financieros necesarios para financiar los proyectos de inversión al mínimo costo y han de contribuir al logro del objetivo financiero de maximizar el valor de la empresa y sus acciones.

Características de las fuentes de financiamiento

Según la (Enciclopedia Económica, 2019) Las principales características de las fuentes de financiamiento son las siguientes:

- Pueden ser internas o externas a la organización.

- Deben obtener un beneficio para que la inversión sea rentable.

- Si poseen participación en las utilidades (ganancias), esta es proporcional a la aportación en capital.

- Son fundamentales para el funcionamiento de la organización.

Tipos de financiamiento

Según (Raffino, 2000) Existen muchos tipos de financiamiento, y muchas formas de acceder a ellos. en principio, distinguiremos entre dos formas entre de financiamiento:

Según quien provee el dinero solicitado:

- Financiamiento propio o interno. Aquel que proviene de los mismos participantes en el proyecto o empresa, es decir, del interior de la organización: de sus inversores, dueños o accionistas, o bien del fruto de sus propias ganancias o actividades lucrativas.

- Financiamiento de terceros o externó. Aquel que proviene de entidades foráneas al proyecto o la empresa, es decir, qué es asignado por otras empresas, particulares o instituciones y que a menudo requiere de cierto tipo de validación, contraprestación o endeudamiento.

Según el tiempo que dura el financiamiento:

- Financiamiento a corto plazo. Cuando es fruto de arreglos que esperan recibir resultados (dividendos, hallazgos o la devolución del dinero) en plazos breves menos de un año.

Según (Banco BASE, 2020)En el caso de la financiación a corto plazo se utiliza 
generalmente para cubrir operaciones vinculadas directamente con los ingresos, es decir, que el beneficio que se consiga sea mayor al costo financiero del crédito. Los tipos de financiamiento a corto plazo Son: crédito comercial crédito bancario, pagarés, línea de crédito, papeles comerciales, financiamiento con base a inventarios.

Ventajas del financiamiento a corto plazo están:

- Se consiguen fácil y rápidamente.

- No cobran tasas de interés muy altas

- El trámite no conserva muchos requisitos y en muchos casos ni siquiera se pide garantía.

- Financiamiento a largo plazo. Cuando es fruto de arreglos que no esperan resultados a corto plazo si no en lapsos mayores (superiores a un año), o incluso no existe obligación de devolución, sino que son aportes desinteresados para sostener la iniciativa en el tiempo.

Según (Banco BASE, 2020) se habla de financiamiento a largo plazo cuando el plazo del pago se extiende más allá de los 5 años irregularmente requiere una garantía. Los tipos de financiamiento a largo plazo incluyen: préstamo hipotecario, emisión de acciones, bonos y arrendamiento financiero.

Fuentes de financiamiento

Según (Raffino, 2000) las principales formas de obtener financiamiento que existen, especialmente aquellas que dependen de terceros (financiamiento externo):

Créditos. Son formas de endeudamiento, pagaderos en diversos lapsos de tiempo y con diversos márgenes de interés. usualmente los otorga una organización financiera (bancos prestamistas, etc), aunque también pueden ser otorgados por instituciones públicas, usualmente en términos más benévolos. las hipotecas, los bonos, los pagarés y las líneas de crédito son ejemplo de ello.

Incorporación de inversionistas. Muchas iniciativas pueden hallar financiamiento abriendo su equipo al ingreso de nuevos elementos, ya sean accionistas nuevos (es decir, vendiendo acciones de la empresa) o nuevos patrocina antes (a los que brindar cambio de publicidad o reconocimiento para las labores de responsabilidad social empresarial).

Préstamos informales. De naturaleza semejante a los créditos, pero otorgados en términos menos formales, pueden provenir de un amigo, un familiar, un prestamista o algo semejante. 
liquidación de bienes o servicios. En caso de que la empresa o el emprendimiento posean bienes que vender o servicios que prestar, puede intentar auto financiarse mediante la oferta de los mismos, siempre y cuando ellos no le impida continuar la existencia, o desnaturalice el proyecto en sí. La venta de espacios publicitarios, por ejemplo, puede ser una vía de autofinanciar un proyecto que tenga exposición masiva.

Importancia de las fuentes de financiamiento

Según (Banco BASE, 2020) el financiamiento es importante para todo tipo de empresas ya que les permite cumplir sus metas operativas y de crecimiento, sin embargo, se deben tomar las decisiones de financiación correctas según los objetivos a corto y largo plazo. El papel del director de Finanzas es evaluar las necesidades de la organización en lo inmediato y a futuro para realizar una planeación óptima que mantenga la competitividad y rentabilidad de la compañía.

Factores que afectan la elección de las fuentes de financiamiento

Según (De Escalón, 2020) lo clasifican en tres factores que afectan la elección de las fuentes de financiamiento.

1. Plazo o periodo de tiempo. Es arriesgado obtener financiamiento a largo plazo para cubrir necesidades a corto plazo. las empresas deben emparejar la fuente de financiamiento con los requerimientos de capital de trabajo permanente es requerido para la expansión de la empresa en el largo plazo. El financiamiento a corto plazo es recomendable para financiar necesidades en el corto plazo como: aumento en las existencias o pago a proveedores.

2. Costo. Obtener financiamiento nunca es de gratis, aun cuando se usan fuentes de financiamiento internas tiene un costo de oportunidad. Los préstamos se vuelven muy caros en periodos donde la tasa de interés está subiendo. Emitir acciones flotantes (Bolsa de Valores), puede costar millones promocionar las acciones para la venta.

3. Monto requerido. Emisión de acciones o la venta de bonos, por los costos administrativos, es usado regularmente para grandes sumas de capital.

préstamos pequeños reducción de acreedores (deudores de la empresa), se puede usar para obtener pequeñas sumas.

La participación pública en favor del emprendimiento en Ecuador

Según (Zamora, 2017) en los últimos 10 años la política pública de apoyo al emprendimiento por parte del Gobierno ecuatoriano se ha enfocado en la creación de normativa, instituciones y programas para facilitar la inclusión económica y el desarrollo 
de actividades productivas en el sector de la economía popular y solidaria (emprendimientos unipersonales, familiares, domésticos, comerciantes minoristas, y talleres artesanales, asociaciones productivas, cooperativas financieras y no financieras), así como en los de sectores estratégicos (recursos hídricos, hidrocarburos, minería, electricidad y telecomunicaciones), tal como se muestra en la tabla 1

A partir de 2010 se crearon varios programas como EmprendEcuador, InnovaEcuador y CreEcuador, todos estos con el propósito de proveer fondos no reembolsables, capacitación y red de contactos a negocios nacientes que tengan un perfil de alto crecimiento, diferenciación e innovación y que permitan dinamizar y diversificar los sectores estratégicos de la economía ecuatoriana. Estos programas fueron llevados a cabo por el Ministerio de coordinación de la producción empleo y competitividad (MCPEC) por aproximadamente 4 años. Sin embargo, la asignación presupuestaria que ha recibido el MCPEC para financiar los programas de apoyo a emprendimientos no ha sido homogénea. según la Tabla 1 se puede ver cómo varían las asignaciones en los años 2012 a 2016.

Tabla 1: Asignaciones presupuestarias ministeriales en programas de emprendimiento

\begin{tabular}{|c|c|c|c|c|c|}
\hline Año & 2012 & 2013 & 2014 & 2015 & 2016 \\
\hline Programa & $\begin{array}{l}\text { Fomento a la } \\
\text { innovación } \\
\text { INNOVAECUADO } \\
\mathrm{R} \\
\text { EmprendEcuador } \\
\text { InnovaEcuador } \\
\text { CreEcuador } \\
\text { Sistema de Apoyo al } \\
\text { inversionista } \\
\end{array}$ & $\begin{array}{l}\text { EmprendEcuador } \\
\text { Fomento a la } \\
\text { innovación } \\
\text { INNOVAECUADO } \\
\mathrm{R} \\
\text { CreEcuador }\end{array}$ & $\begin{array}{l}\text { EmprendEcuado } \\
\mathrm{r}\end{array}$ & $\begin{array}{ll}\begin{array}{l}\text { Proyecto } \\
\text { inversión y }\end{array} & \text { de } \\
\text { cooperación } & \\
\text { externa } & \text { no } \\
\text { reembolsable } & \\
\text { programa } & \\
\text { EMPRENDAMO } \\
\text { S }\end{array}$ & $\begin{array}{lr}\text { Proyecto } & \text { de } \\
\text { inversión y } & \text { de } \\
\text { cooperación } & \\
\text { externa } & \text { no } \\
\text { reembolsable } & \\
\text { programa } & \\
\text { EMPRENDAMO } \\
\text { S }\end{array}$ \\
\hline $\begin{array}{c}\text { Asignació } \\
n\end{array}$ & $\$ 4.965 .327,74$ & $\$ 214.521,13$ & $\$ 115.000,00$ & $\$ 41.000,00$ & $\$ 300.000,00$ \\
\hline Porcentaje & $\begin{array}{l}25 \% \text { del presupuesto } \\
\text { del plan anual de } \\
\text { inversiones } \\
\text { MCPEC }\end{array}$ & $\begin{array}{l}1,46 \% \text { del } \\
\text { presupuesto del plan } \\
\text { anual de inversiones } \\
\text { del MCPEC }\end{array}$ & $\begin{array}{lr}6,82 \% & \text { del } \\
\text { presupuesto } & \text { del } \\
\text { plan anual } & \text { de } \\
\text { inversiones } & \text { del } \\
\text { MCPEC } & \end{array}$ & $\begin{array}{lr}0,11 \quad \% & \text { del } \\
\text { presupuesto } & \text { del } \\
\text { plan anual } & \text { de } \\
\text { inversiones } & \text { del } \\
\text { MCPEC } & \end{array}$ & $\begin{array}{lrr}4,88 \quad \% & \text { del } \\
\text { presupuesto } & \text { del } \\
\text { plan anual } & \text { de } \\
\text { inversiones } & \text { del } \\
\text { MCPEC } & \\
\end{array}$ \\
\hline
\end{tabular}

Fuente: (Ministerio de Finanzas del Ecuador, 2016)

\section{Metodología:}

Este estudio se fundamentó en un enfoque cualitativo y cuantitativo. Cualitativo porque su preocupación no es prioritariamente medir sino cualificar y describir el fenómeno social a partir de rasgos determinantes según sean percibidos por los elementos mismos que están dentro de la situación estudiada, según el autor (Bernal, 2010); mientras que la modalidad cuantitativa según el mismo autor es aquel que utiliza valores numéricos para estudiar un fenómeno como consecuencia obtiene conclusiones que pueden ser expresadas de forma matemática; con un proceso deductivo al alcance descriptivo ya que detalla una realidad.

Para el desarrollo de la presente investigación se usó diferentes métodos como el teórico, al igual que el método analítico-sintético para la revisión de la literatura, en lo 
que tiene que ver a los aspectos teóricos necesarios. También se usó el método de dialéctico, inductivo y deductivo ya que mediante la aplicación de estos métodos se han se realizó el análisis del tema.

Para fundamentar teóricamente el presente trabajo se utilizó la investigación documental además se aplicó la investigación de campo, con el objeto de recabar información de los emprendedores del cantón Riobamba. luego a partir de datos relacionados con otros desarrollan unas generalizaciones (Inducción) qué, a su vez, guardan relación con otras teorías ya existentes (explicación). se desarrolló esta investigación para conocer la realidad, a través de encuestas con la aplicación de cuestionarios para conocer la situación actual.

la población es un conjunto de elementos que contienen ciertas características que se pretenden estudiar. por esta razón entre la población y la muestra existe un carácter inductivo, esperando que la parte observada (en este caso la muestra) sea representativa de la realidad (entiéndase aquí a la población); para de esta forma garantizar las conclusiones extraídas del estudio. (Bernal, 2010)

La investigación se realizó para un universo de emprendedores de diferentes sectores productivos del cantón Riobamba, los mismos se tomaron de una base de datos otorgada por el GAD de Riobamba, MIES e IEPS; por tal motivo una de las variables de estratificación fue seleccionar los emprendedores activos y con número de contacto actualizado. De este modo se determinaron 74 emprendedores como población en estudio, por lo que no se procedió a calcular la muestra y se aplicó la encuesta a toda la población, con la utilización de medios virtuales y un software especializado como es el Forms.

\section{Resultados:}

Una vez tabulados los resultados de las preguntas realizadas mediante la encuesta aplicada a los emprendedores del cantón Riobamba, se obtuvo los siguientes resultados:

Pregunta 1. ¿Cuál ha sido la fuente de Financiamiento para iniciar o fortalecer su negocio?

Fuente de Financiamiento para iniciar o fortalecer su negocio

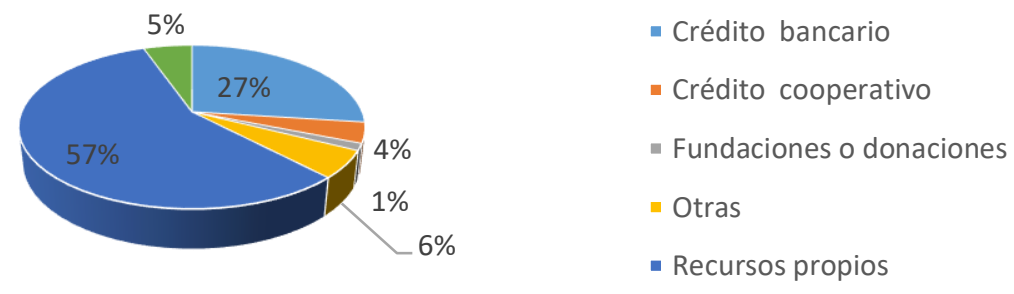

Gráfico 1. Fuente de financiamiento para iniciar o fortalecer su negocio Fuente: Elaboración propia 
Interpretación: De acuerdo con la encuesta realizada podemos verificar que la mayoría de los emprendedores, el $57 \%$ se financio con recursos propios, el $27 \%$ con crédito bancario; el $4 \%$ con Cooperativas de ahorro y crédito, el $1 \%$ con fundaciones o donaciones, el $6 \%$ con otras fuentes de financiamiento y un $5 \%$ no contesta la pregunta. Lo expuesto evidencia que los emprendedores del cantón Riobamba prefieren iniciar su negocio con recursos propios.

Pregunta 2. ¿Usted accedió a un crédito financiero por medio de una asesoría previa?

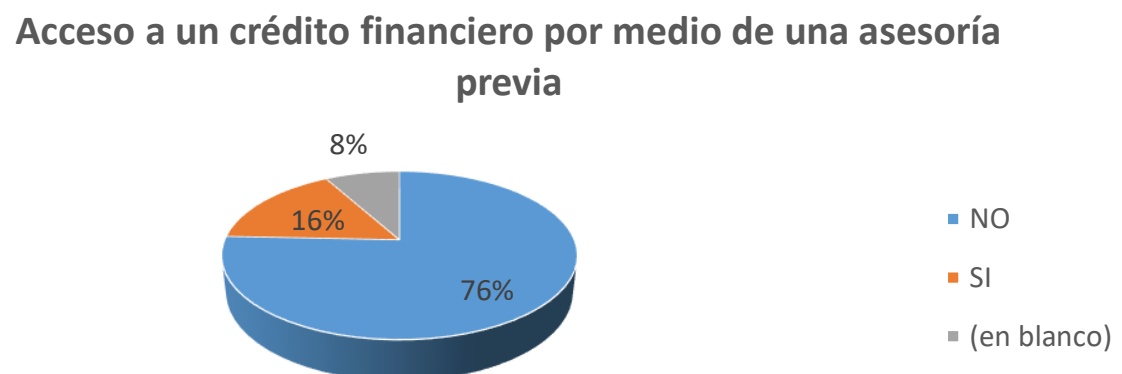

Gráfico 2. Acceso a un crédito financiero por medio de una asesoría previa Fuente: Elaboración propia

Interpretación: En esta pregunta se puede evidenciar que el $76 \%$ de los emprendedores no tuvieron una asesoría previa sobre el acceso al crédito financiero, y tan solo el $16 \%$ si contaron con asesoría sobre el acceso al crédito, de igual manera un $8 \%$ se abstiene de contestar la pregunta.

Pregunta 3. ¿En el último año usted obtuvo algún crédito para potenciar su negocio?

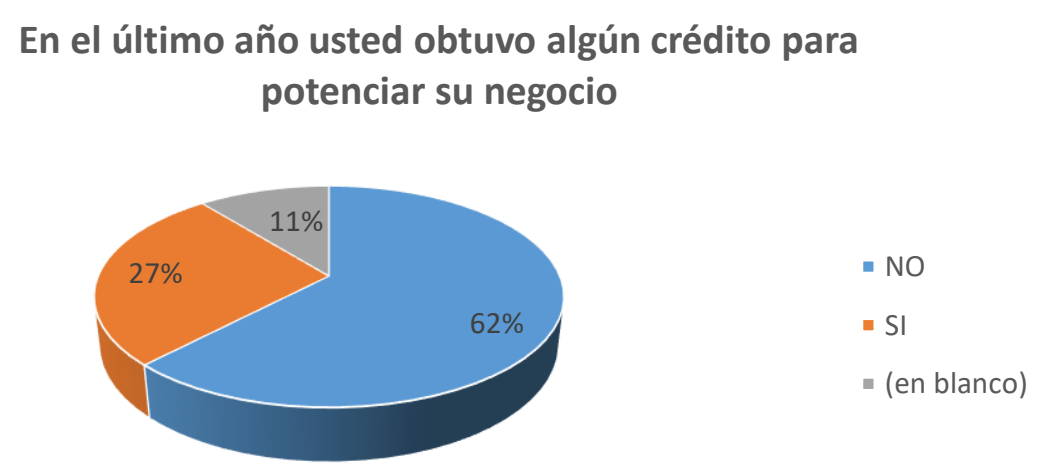

Gráfico 3. En el último año usted obtuvo algún crédito para potenciar su negocio Fuente: Elaboración propia

Interpretación: En esta pregunta tenemos que el $62 \%$ de los emprendedores encuestadas no han obtenido créditos en el último año y el $27 \%$ si han gestionado crédito para potenciar su negocio, así mismo tenemos un $11 \%$ de abstención en la respuesta, es decir aquellas personas que dejaron en blanco su respuesta. 
Pregunta 4. Si la respuesta de la pregunta número tres fue negativa escoja una de las siguientes opciones:

Si la respuesta de la pregunta número tres fue negativa escoja una de las siguientes opciones:

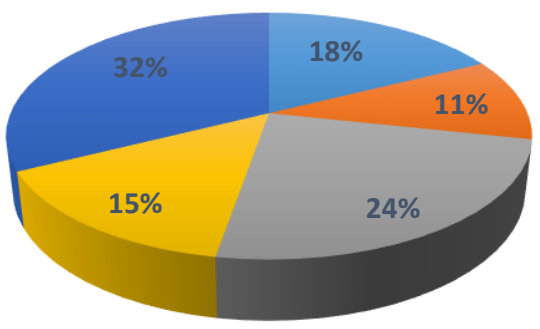

Desconfianza en instituciones crediticias

Desconoce proceso crediticio

- Incumplimiento de requisitos

No necesita

Gráfico 4. Si la respuesta de la pregunta número tres fue negativa escoja una de las siguientes opciones

Fuente: Elaboración propia

Interpretación: Los resultados en esta pregunta permiten evidenciar las razones del porque los emprendedores no trabajan con crédito, es así que el $24 \%$ de los emprendedores no cumple con los requisitos que impone el sistema financiero, el $18 \%$ tiene desconfianza en las instituciones crediticias, el 15\% no necesita financiamiento, el $11 \%$ desconoce el proceso crediticio, y el $32 \%$ no contesta la pregunta.

Pregunta 5. Si la respuesta a la pregunta número tres fue positiva indique con qué tasa de interés

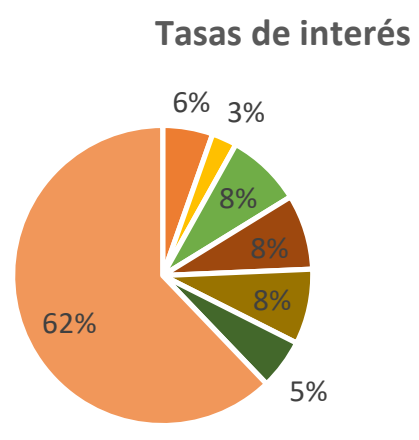

- $0-5 \%$

$-5,1-10 \%$

$=10,1-15 \%$

- $16,1-20 \%$

- Sobre el $20 \%$

- Ninguna

- (en blanco)

Gráfico 5. Tasas de interés

Fuente: Elaboración propia

Interpretación: En esta pregunta se puede evidenciar que el $8 \%$ de los emprendedores paga una tasa de interés superior al $20 \%$, el otro $8 \%$ paga una tasa de interés entre $16,1 \%$ y $20 \%$, el siguiente $8 \%$ paga una tasa de interés entre el $10,1 \%$ y el $15 \%$, el $6 \%$ de emprendedores paga una tasa de interés entre el 0 y $5 \%$, un $3 \%$ paga una tasa de interés entre el 5,1 y $10 \%$, y el $62 \%$ no trabaja con crédito. 
Pregunta 6. Si la respuesta a la pregunta número tres fue positiva indique en qué institución financiera

Indique en qué institución financiera obtuvo el crédito
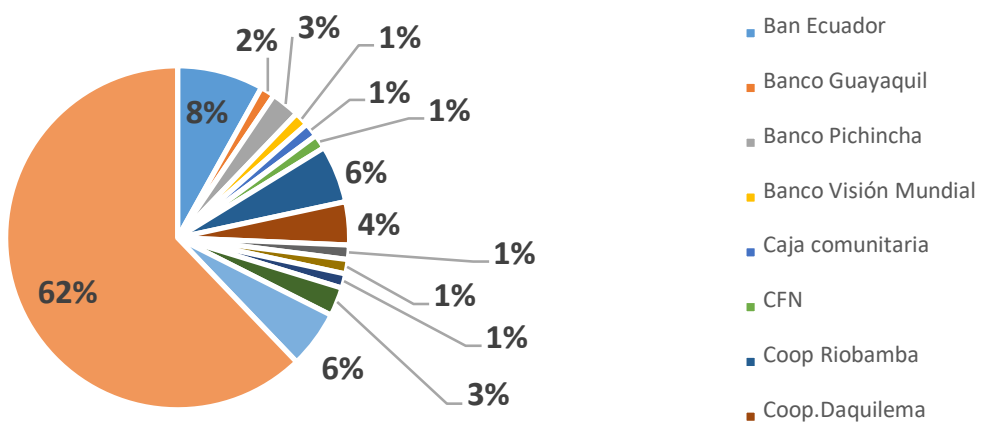

Gráfico 6. Con que institución financiera se financia Fuente: Elaboración propia

Interpretación: Una vez analizados los resultados de la investigación en lo que corresponde a que institución financiera le financia al emprendedor, tenemos que el $8 \%$ trabaja con BanEcuador, el 6\% con la Caja comunitaria, el 6\% con la Cooperativa Riobamba, el 4\% con la Cooperativa Daquilema, el 3\% con Banco del Pichincha, el 2\% con Banco de Guayaquil entre los principales, y finalmente un $62 \%$ no trabaja con ninguna entidad financiera.

Pregunta 7. Si la respuesta de la pregunta número tres fue positiva indique con qué monto

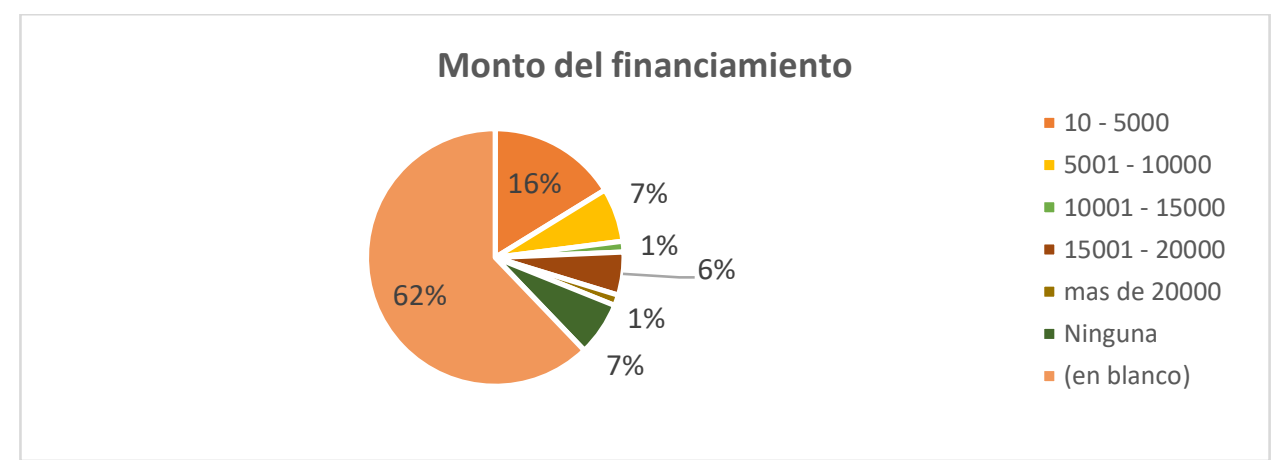

Gráfico 7. Monto del financiamiento

Fuente: Elaboración propia

Interpretación: Una vez analizados los resultados de la investigación en lo que corresponde al Monto del financiamiento, el 16\% de los emprendedores obtuvo un préstamo entre 10 y 5000 dólares, el 7\% de obtuvo un préstamo entre 5001 y 10000 dólares, el 6\% se financio con un monto entre 15001 y 20000 dólares, el $1 \%$ se financio entre 10001 y 15000 dólares, y un $1 \%$ se financio con un valor superior a los 20000 dólares, y el restante $62 \%$ no responde ya que no trabaja con financiamiento. 
Pregunta 8. ¿Considera que el sistema financiero nacional contribuye positivamente al crecimiento y fortalecimiento de los emprendimientos en el cantón Riobamba?
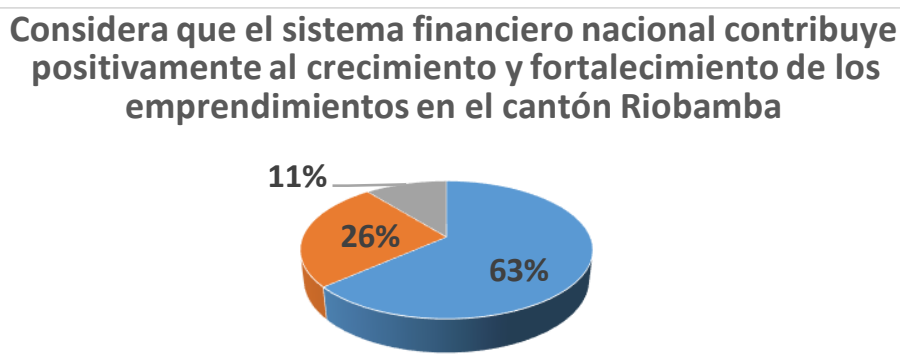

- NO

- $\mathrm{SI}$

- en blanco

Gráfico 8. ¿Considera que el sistema financiero nacional contribuye positivamente al crecimiento y fortalecimiento de los emprendimientos en el cantón Riobamba?

Fuente: Elaboración propia

Interpretación: En lo que corresponde a esta pregunta, se observa que el $63 \%$ de los emprendedores creen que el sistema financiero no contribuye positivamente con el crecimiento y fortalecimiento de los emprendimientos en el cantón Riobamba, el $26 \%$ cree que si contribuye y el $11 \%$ restante no contesta la pregunta. Bajo esta perspectiva es necesario que las instituciones financieras adopten políticas de ayuda al fortalecimiento de los emprendimientos, disminuyendo las tasas de interés, flexibilizando los requisitos, etc.

Pregunta 9. ¿Cuál es la utilidad neta de su negocio al mes, antes de la emergencia sanitaria?

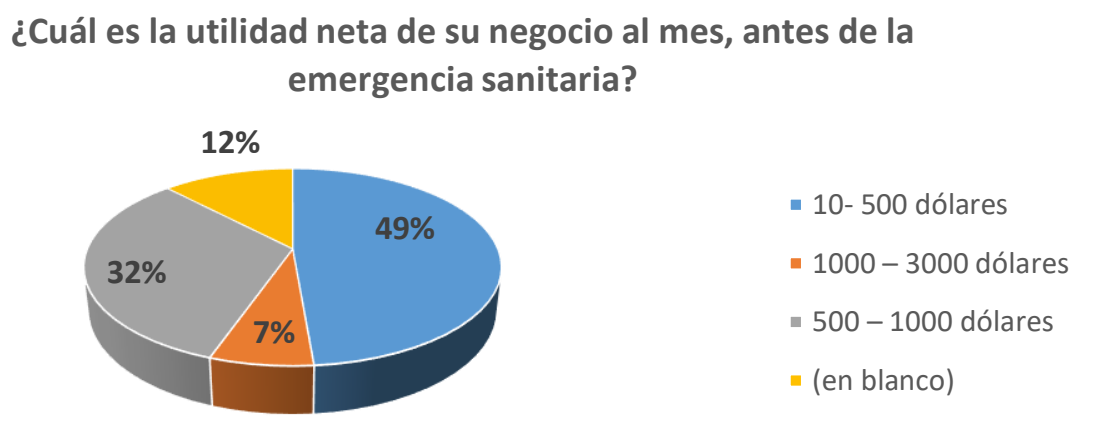

Gráfico 9. ¿Cuál es la utilidad neta de su negocio al mes, antes de la emergencia sanitaria? Fuente: Elaboración propia

Interpretación: En esta pregunta se puede apreciar que el $49 \%$ de los emprendedores antes de la emergencia sanitaria tenía una utilidad mensual entre 10 y 500 dólares, el 32\% tenía una utilidad mensual entre los 500 y 1000 dólares, el $7 \%$ tenía una utilidad mensual entre 1000 y 3000 dólares, y el 12\% de los encuestados no responde esta pregunta. 
Pregunta 10. ¿Cuál es la utilidad neta de su negocio al mes, durante la emergencia sanitaria?

Utilidad neta de su negocio al mes, durante la emergencia sanitaria

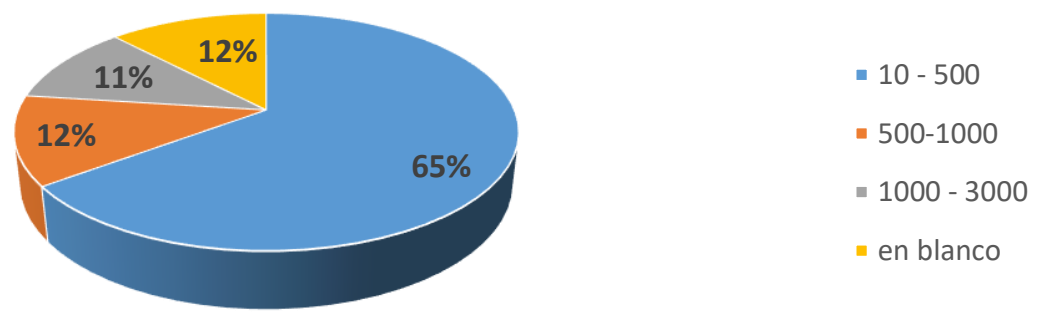

Gráfico 10. ¿Cuál es la utilidad neta de su negocio al mes, durante la emergencia sanitaria? Fuente: Elaboración propia

Interpretación: En esta pregunta se puede observar que el 65\% de los emprendedores durante la emergencia sanitaria tiene una utilidad mensual entre 10 y 500 dólares, el 12\% tiene una utilidad mensual entre los 500 y 1000 dólares, el $11 \%$ tiene una utilidad mensual entre 1000 y 3000 dólares, y el 12\% de los encuestados no responde esta pregunta.

El financiamiento es sin lugar a duda un eje crítico en la sostenibilidad de los emprendimientos, de ahí que es muy importante considerar variables como la seguridad, la rentabilidad y el riesgo, antes de adoptar una fuente de financiamiento. De esta investigación, se puede apreciar que en el cantón Riobamba el 57\% de los emprendimientos se financian con fondos propios, y un $27 \%$ se financian con Crédito bancario por lo que se puede deducir que los emprendedores Riobambeños prefieren la seguridad de usar sus propios fondos a la rentabilidad que puede generar el apalancamiento financiero. Esta situación a nivel nacional mantiene y se refuerza según (Lasio \& Zambrano, 2016) En Ecuador el 98 \% de los emprendimientos son financiados con fondos propios, alcanzando una cobertura del $74 \%$.

Según la encuesta aplicada el $27 \%$ de emprendedores ha realizado una operación de crédito en el sistema financiero, y en estas operaciones financieras se observa que las tasas de interés son sumamente variables y fluctúan desde el $5 \%$ hasta valores superiores al 20\%, esta realidad, en las tasas de interés repercute directamente en su sostenibilidad financiera, ya que el endeudamiento si se lo toma a una tasa muy alta afecta directamente a la rentabilidad de los emprendimientos y en lugar de ser una ayuda para el crecimiento y sostenibilidad podría ocasionar la quiebra o el cierre de los mismos. De ahí que es muy importante de acuerdo con (Pilay, Palacios, Muñoz, Benavides, \& Pico, 2019) realizar un análisis previo al financiamiento, e identificar las prioridades concretas para impulsar el crecimiento, asegurando la profesionalización de la unidad gerencial frente a un mercado competitivo.

Para el $49 \%$ de los emprendedores del cantón Riobamba la utilidad mensual antes de la 
pandemia esta entre los 10 y 500 dólares, y para el siguiente grupo que representa el $32 \%$ su utilidad esta entre los 500 y 1000 dólares, situación que se ve afectada con la emergencia sanitaria, ya que se incrementa al $65 \%$ la cantidad de emprendedores que generan la utilidad más baja ubicada entre 10 y 500 dólares, y el grupo que generaba beneficios entre los 500 y 1000 dólares se reduce al 12\%, es decir este segmento es el más afectado, por lo que es necesario considerar lo que dice (Suárez, 2014)

Las empresas deben realizar un proceso de toma de decisiones sistemático, en donde el principal enfoque estratégico son los resultados empresariales que se proyecta, sin embargo las empresas deben tomar acciones remediales cuando no se cumplen las proyecciones, por lo tanto es importante que en las empresas se establezcan acciones estratégicas sostenibles. Por lo expuesto es responsabilidad del estado, Gobiernos seccionales, ONGs, universidades entre otros emprender programas de educación financiera para que los emprendedores conozcan las bondades del endeudamiento, de igual manera el estado conjuntamente con las entidades financieras deberían reducir las tasa de financiamiento y mejorar las condiciones generales del crédito, para que los emprendedores puedan optar por el financiamiento en momentos de crisis, y de esta manera puedan asegurar la sostenibilidad de sus emprendimientos.

\section{Conclusiones:}

- La investigación de campo permitió determinar que el 57\% de los emprendedores del cantón Riobamba, inicio su emprendimiento con recursos propios ante el desconocimiento, el exceso de requisitos que le exige las entidades bancarias o la desconfianza que tienen los emprendedores en el sistema financiero.

- El diagnóstico de las fuentes de financiamiento nos ha permitido determinar que el 27\% de los emprendimientos del cantón Riobamba se financiaron a través del sistema financiero en algún momento de su operación.

- Por medio de la investigación realizada se logró determinar que el $49 \%$ de los emprendedores del cantón Riobamba generaban una utilidad mensual antes de la pandemia entre los 10 y 500 dólares, y para el 32\% el beneficio se ubicaba entre los 500 y 1000 dólares, esta situación se ve afectada con la emergencia sanitaria, ya que se incrementa al $65 \%$ la cantidad de emprendedores que generan utilidad entre 10 y 500 dólares, y el grupo que generaba beneficios entre los 500 y 1000 dólares se reduce al $12 \%$, es decir gran parte de este segmento migro a la escala inferior.

- Es importante que el estado juntamente con las entidades financieras establezca un programa específico de financiamiento en el que se fije una sola tasa de interés para el desarrollo de emprendimientos, y a la vez se mejore las demás condiciones del crédito, como el monto, el plazo y las garantías, para que los emprendedores 
puedan optar por un financiamiento que contribuya al crecimiento y la sostenibilidad de sus emprendimientos.

\section{Referencias Bibliográficas}

Aguirre, D., \& Andrango, S. (2011). Preferencias en el uso de productos y servicios financieros que ofrecen las instituciones del Sistema Financiero Regulado ecuatoriano.

Banco BASE. (2020). Grupo Financiero BASE. Obtenido de https://www.bancobase.com/gobierno-corporativo/estados-financieros-anuales

Bernal, C. (2010). Metodología de la Investigación. Bogota: Pearson Educación.

Daniels, C., Herrington, M., \& Kew, P. (2016). Report on Entrepreneurial Financing. GEN Global Entrepreneurship Monitor, 83.

De Escalón, S. (2020). GESTIÓN EMPRESARIAL BI. Obtenido de https://empresaygestionbi.weebly.com/31-fuentes-de-financiamiento.html

Enciclopedia Económica. (2019). Enciclopedia Económica. Obtenido de https://enciclopediaeconomica.com/fuentes-de-financiamiento/

INEC. (2018). Encuesta Estructural Empresarial. Quito. Obtenido de https://www.ecuadorencifras.gob.ec/documentos/webinec/Estadisticas_Economicas/Encuesta_Estructural_Empresarial/2018/2018_E NESEM_Boletin_tecnico.pdf

Lasio, V., \& Zambrano, J. (2016). Financiamiento para emprendedores. ESPAE-ESPOL, 8.

Martins, N. (Enero de 2021). OBERLO. Obtenido de https://www.oberlo.es/blog/definicion-y-significado-emprendimiento

Ministerio de Finanzas del Ecuador. (2016). Plan Anual de Inversiones (años 2012, 2013 , 2014, 2015, 2016). Quito.

Pilay, E., Palacios, J., Muñoz, M., Benavides, A., \& Pico, E. (2019). Las fuentes de financiamiento como estrategias de competitividad en las Pymes en la provincia de Santa Elena. Espirales, 8 Obtenido de http://www.revistaespirales.com/index.php/es/article/view/467/418

Raffino, M. (Septiembre de 2000). Concepto.de. Obtenido de https://concepto.de/financiamiento/\#ixzz6npQmGxrY

Roca , R. (2002). La tasa de interés y sus principales determinantes. Obtenido de http://economia.unmsm.edu.pe/org/arch_iie/arch_invest/doc_inv_DI-02-003.pdf

Román, C. (2018). El crédito como aporte para el desarrollo de las actividades productivas, en la provincia de El Oro, caso; Banco Delbank y solidario. Periodo 2005 al $2016 . \quad$ Obtenido de http://dspace.utpl.edu.ec/bitstream/20.500.11962/22591/1/Rom\%C3\%A1n\%20L $\% \mathrm{C} 3 \% \mathrm{~B} 3$ pez\%2C\%20Cristhian\%20Vinicio.pdf

Suárez, L. (2014). Administración gestión organizacional y enfoque empresarial. Bogotá: Trillas.

Torre, B., Fresno, M., \& Centero, M. (2015). Universidad de cantabria. Obtenido de https://ocw.unican.es/course/view.php?id=50\&section=1 
Zamora, C. (2017). La importancia del emprendimiento en la economía: el caso de Ecuador. $\quad$ Espacios, 12 Obtenido de https://www.revistaespacios.com/a18v39n07/a18v39n07p15.pdf

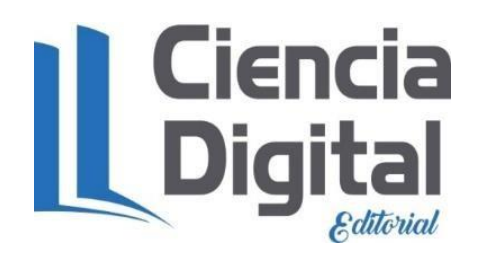




\section{PARA CITAR EL ARTÍCULO INDEXADO.}

Avalos Peñafiel, V. G., Cevallos Silva, W. P., \& Torres Guananga, G. P. (2021). El financiamiento un eje crítico en la sostenibilidad de los emprendimientos en el cantón Riobamba. ConcienciaDigital, $4(1.2)$ 299-315. https://doi.org/10.33262/concienciadigital.v4i1.2.1598

\section{LCiencia}

El artículo que se publica es de exclusiva responsabilidad de los autores y no necesariamente reflejan el pensamiento de la Revista Conciencia Digital.

El artículo queda en propiedad de la revista y, por tanto, su publicación parcial y/o total en otro medio tiene que ser autorizado por el director de la Revista Conciencia Digital.

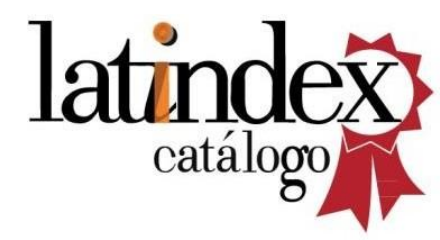

